E R R A T U M

Corrigendum to Volume 12, Number 5, p. 356-366

Published online: 19 May 2010

(CFESEO 2010

\title{
TTD consensus document on the diagnosis and management of hereditary colorectal cancer
}

Pedro Pérez Segura • Carmen Guillén Alonso • Teresa Ramón y Cajal •

Raquel Serrano Blanch $\cdot$ Enrique Aranda

There was a mistake in the list of authors of the article entitled "TTD CONSENSUS DOCUMENT ON THE DIAGNOSIS AND MANAGEMENT OF HEREDITARY COLORECTAL CANCER”. The correct list of authors is: Pedro Pérez Segura, Carmen Guillén Ponce, Teresa Ramón y Cajal, Raquel Serrano Blanch, Enrique Aranda

The original version of the article can be found in:

Clin Trans Oncol (2010) 12:356-366

DOI 10.1007/s12094-010-0517-5 